Revista Digital Año 7. No 9 - Año 2016. --pág. 1-104

ISSN 1853-1393

Resistencia. Chaco. Argentina - 2016

\title{
INCLUSIÓN, INFANCIAS Y PRÁCTICA DOCENTE. SUPUESTOS Y TENSIONES EN LA PROPUESTA CURRICULAR PARA LA EDUCACIÓN INICIAL DE LA PROVINCIA DEL CHACO
}

\section{INCLUSION, CHILDHOOD AND TEACHING PRACTICE. ASSUMPTIONS AND TENSIONS IN THE CURRICULUMPROPOSED FOR THE INITIAL EDUCATION OF THE PROVINCE OF CHACO}

Prof. Mariela del Carmen Fogar ${ }^{1}$ - Prof. Carlos Alberto Silva ${ }^{2}$

Fecha de recepción: 09-08-2016

Fecha de aceptación y versión final: 11-10-2016

Resumen: Se presentan avances de una indagación teórica sobre el Currículum de Educación Inicial de la Provincia del Chaco, a través de las categorías políticas inclusivas, educación inicial e infancias. El enfoque teórico se entiende como una forma de representarse la realidad a través de conceptos que operan como supuestos.

La indagación sigue una lógica cualitativa con análisis documental. Se inscribe en el proyecto de investigación en curso "Políticas públicas para la infancia: Incidencia de la obligatoriedad del Nivel Inicial en la construcción de la subjetividad de niñas y niños del barrio Molina Punta de Resistencia, Chaco", encarado por el equipo de cátedra Seminario Educación y Sociedad. El cambio curricular en el NI, formó parte de las políticas educativas inclusivas para la infancia implementadas por el gobierno nacional en el período 2003/2015.

Se asume la educación como práctica histórica, ligada a condiciones materiales, sociales y simbólicas, co-productora de subjetividades (Puiggros, 1995) y de lo social (Frigerio, 2001). Frigerio (2005) y McLaren (1998) la entienden como práctica política, que incluye una política cultural y económica de distribución de conocimientos, deseos e identidades.

En este artículo se analiza el currículum en vinculación con los procesos históricos en que se inscribe y las tensiones en la dinámica entre la propuesta curricular ajustada a una idea de la función inclusiva de la educación, y su construcción en la práctica.

Palabras clave: políticas inclusivas - educación inicial - currículum- infancias

Abstract: Recentre search developments about theoretical inquiry into the Curriculum of Initial Education of the province of Chaco, through inclusive political categories, initial education and childhood. The theoretical approach is understood as a way of representing reality through concepts that operate as assumptions.

The inquiry follows a qualitative logic with documentary analysis. He is part of the ongoing research project "public policies for children: incidence of the obligatory nature of the initial level in the construction of the subjectivity of children from the neighborhood Molina Punta from Resistencia, Chaco", undertaken by Seminary education and society. Curriculum change in $\mathrm{NI}$, was part of inclusive education policies for children implemented by the national Government in the period 2003 / 2015.

Education as a practice linked to material, social and symbolic conditions, historical, co-producer of subjectivities (Puiggros, 1995) and social (Frigerio, 2001) is assumed. Frigerio (2005) and McLaren (1998) understand this as a political practice, which includes a cultural and economic policy of distribution of knowledge, desires and identities.

This article analyzes the curriculum in association with historical processes on which is inscribed and tensions in the dynamics between the proposed curriculum adjusted to an idea of inclusive education function, and its construction in practice.

Key words: inclusive policies - initial education - curriculum-childhoods

\footnotetext{
1 Profesora Adjunta a cargo de las cátedras Seminario Educación y Sociedad y Corrientes del pensamiento contemporáneo de la Facultad de Humanidades de la UNNE. Domicilio: PIO XII 446 Resistencia (Chaco). Teléfono: 4-571240. Correo electrónico: marieladelcarmenfogar@gmail.com.

2 Profesor Auxiliar de la cátedra Seminario Educación y Sociedad de la Facultad de Humanidades de la UNNE. Domicilio: Av. San Martín 1929, Dto. 3- - Resistencia (Chaco). Teléfono: 4-4489508. Correo electrónico: carlosilva@gmail.com.
} 


\section{Introducción}

En este artículo se presentan resultados de una indagación teórica sobre el Currículum de Educación Inicial (CEI) de la Provincia del Chaco, a través de las categorías políticas inclusivas, educación inicial e infancias. El enfoque teórico se entiende como una forma de representarse la realidad a través de conceptos que operan como supuestos.

$\mathrm{La}$ indagación sigue una lógica cualitativa con análisis documental. Se inscribe en el proyecto de investigación en curso "Políticas públicas para la infancia: Incidencia de la obligatoriedad del Nivel Inicial en la construcción de la subjetividad de niñas y niños del barrio Molina Punta de Resistencia, Chaco", encarado por el equipo de cátedra Seminario Educación y Sociedad.

El proyecto de investigación se inscribe, a su vez, en la propuesta de trabajo desarrollada en la cátedra Seminario Educación y Sociedad- asignatura de las carreas Profesorado/Licenciatura en Educación Inicial- entre 2013 y 2016, centrada en la función social de la Educación Inicial y el desempeño de los docentes como agentes del Estado, desde la apuesta por la inclusión en el marco de un Estado que, en la década pasada estuvo presente a través de políticas tendientes a garantizar la ampliación de la obligatoriedad de la Educación Inicial. El proyecto fue diseñado en 2014 en un contexto nacional e internacional que se modificó a partir de diciembre de 2015, como consecuencia de profundas transformaciones de las relaciones económicas y geopolíticas mundiales, caracterizadas, muy recientemente como desglobalización.

El cambio curricular formó parte de las políticas educativas inclusivas para la infancia, desarrolladas en la Argentina en la década antes mencionada. En este artículo se analiza el currículum para la Educación Inicial, en vinculación con los procesos históricos en que se inscribe y las tensiones en la dinámica entre la propuesta curricular ajustada a una idea de la función inclusiva de la educación, y su construcción en la práctica.

La educación no es una realidad universal que produzca los mismos efectos en todos los sujetos. Es una práctica histórica, ligada a las condiciones materiales, sociales y simbólicas en que se desarrolla. Como co-productora de subjetividades, la educación opera como componente de la construcción social. Por ello, como sostienen Frigerio (2005) y McLaren (1998), la educación es una práctica política, que incluye una política cultural y una política económica de distribución de conocimientos, deseos e identidades. En esa línea, para Davini (2006) la neutralidad de la educación es una ilusión. Desde esta perspectiva, educación y currículum son pues territorios donde tienen lugar conflictos simbólicos que expresan la conflictividad social.

A pesar de que el carácter político de la educación ha sido largamente fundamentado por epistemólogos, pedagogos y sociólogos del campo, en la práctica, persiste aun la creencia de que la neutralidad es el principio ético que debe guiar la educación, y condición de su eficacia. La pretensión de neutralidad tiene sus raíces en el dominio del positivismo, que al postular la posibilidad de un conocimiento universal y absoluto, generó las condiciones para el dominio de una pedagogía que posiciona a los docentes como portadores de ese conocimiento y autoridad única e indiscutible para la transmisión de determinadas normas y valores, también considerados universales. Sobre la base de estas creencias, como señalan Batallán y Campanini (1990: 43), la educación y la escuela desvalorizan la vida extraescolar, por lo que construyen niños "infantilizados", privados de sus capacidades de elaborar críticamente experiencias y saberes.

Esa concepción epistemológica se conjuga con la ideología liberal, que se enraíza en los principios del contractualismo de Locke enunciados en el siglo XVII, se consolida con la llustración, y en los años '50 del siglo XX encuentra sus fundamentos 
sociológicos en el funcionalismo de raíz parsoniana, que asignó a la educación una función de selección y distribución del capital humano, en función de la división social del trabajo, como contribución a la construcción de un orden social, pretendidamente ideal, que requiere que los niños no sólo aprendan las habilidades y destrezas que demanda el mercado de trabajo, sino también acepten el sistema de valores básicos imperantes en la sociedad. Esa concepción de la función de la educación se basa en el supuesto de la igualdad de punto de partida de los estudiantes, que Parsons concibe como competidores, capaces de diferenciarse entre sí según sus propios méritos.En ese esquema económico-social, como sostiene Cohn (2005) se asigna a los niños un lugar definido, sin consideración de sus acciones y sus representaciones simbólicas. Desde esa lógica, se legitiman aquellas prácticas que tienden a mantener el statu quo propio de las sociedades capitalistas. Con respecto a la infancia, esas prácticas contribuyen a legitimar las relaciones de dominio (del adulto y de las instituciones que lo representan) -subordinación (de niños y niñas), bajo el supuesto de que el adulto es un sujeto emancipado y completamente libre con respecto a los poderes económicos, políticos y culturales que operan en la vida social.

Ambos supuestos -la neutralidad del conocimiento y de la educación y la función uniformizadora de esta última- son constituyentes de la matriz ideológica sobre la que se fundó el sistema educativo argentino, casi 70 años antes del desarrollo de la sociología funcionalista. Estos supuestos no han hecho más que negar el carácter dinámico y conflictivo de lo social ydel conocimiento. Por lo mismo, y a través de su versión remozada en la década de 1990, se han traducido en currículum escolares funcionales a los intereses del mercado. En esa década, las reformas educativas gestadas y financiadas desde el FMl y el BM, respondieron claramente al proyecto de la nueva alianza estratégica entre neoconservadores y neoliberales. Sociólogos de la educación, de la envergadura de Apple y Giroux, han analizado los supuestos racistas subyacentes en las políticas neoliberales y los mecanismos de exclusión que emplean -vía selección de los "más aptos"i-.Gentili (1998) ha señalado, asimismo, el carácter estratégico de la educación en la política imperialista de Estados Unidos, que después del período de imposición de dictaduras en América Latina, optó por la profundización de la dominación por la vía ideológica, plasmada en el programa conocido como Consenso de Washington. Desde los noventa, la nueva forma de dominación se despliega en forma sofisticada a través del reemplazo de la estrategia dictatorial por la estrategia mercantil del consumismo, orientada a producir sujetos a la medida del mercado.

En la construcción de las subjetividades requeridas por el sistema, juegan un papel preponderante los medios de comunicación de masas que nucleados en torno a monopolios de la información, diseñan, producen y reproducen un orden simbólico. Los medios no sólo venden productos y valores, sino que construyen realidad. Niños y adolescentes son concebidos por el mercado, como consumidores, susceptibles de ser moldeados por las empresas que los reducen a objetos de su política de acumulación. Bustelo (2007) analiza el modo en que la empresa Disney, principal exponente del imperio de la industria cultural infantil, formatea las experiencias y representaciones de niños/as y adolescentes, a través de dispositivos que construyen "una ideología de encantamiento en un mundo libre de desigualdades, sin pobreza, sin conflictos, sin sufrimiento, sin criminalidad, sin guerras y sobre todo, libre de la política. $Y$ lo más relevante: hace de niños, niñas $y$ adolescentes consumidores y no ciudadanos".

Desde la perspectiva del psicoanálisis, la realidad se entiende en un doble sentido: como realidad objetiva, pero también como realidad que se construye a partir de la relación con el otro, como figura identitaria, en tanto el yo o subjetividad, es una construcción con otros significativos, que permite la instauración del aparato psíquico. Son las relaciones con los otros sujetos, las que posibilitan la construcción del 
esquema corporal y el lenguaje; sin los otros, la relación con el mundo, es imposible. Aguado y Portal (1991) afirman que la identidad se estructura sobre la pregunta ¿quién soy frente al otro? La identidad es un proceso constituido por prácticas con un significado cultural, ideológico, social e histórico, que se expresan en formas de hacer, de hablar, de pensar, de concebir el mundo y de organizar la vida.

El yo freudiano, como significante, es siempre alienado, pues se funda no en los propios deseos sino en el deseo del otro, de manera tal que el deseo de uno es el deseo del otro. Esa alienación se supera individualmente, en la dialéctica del deseo, ya que el goce, punto tensionante, es imposible y por tanto, permanente. Lo social, el grupo, los lazos sociales, se fundan en la necesidad de establecer un vínculo gracias al cual los sujetos se aseguren un mínimo de ser, un nosotros que haga posible la construcción de un yo y el goce que les fue negado por el padre de la horda primitiva que Freüd inventa en "Totem y Tabú". Así, el goce se constituye en el motivo principal de la vida en sociedad y encuentra su consistencia gracias al símbolo. No hay una esencia del sujeto; éste se define como ser a partir del lenguaje, de los dichos que le fueron atribuidos al nacer. No habiendo un significante último al cual remitirse, no llega a definirse por completo. En la imagen del otro, el sujeto reconoce algo de lo que a él le concierne y lo identifica (la etnia, la religión, la ideología, la cultura), denominación signo de algo de reconocimiento, que anticipa la imagen de sí mismo. Desde esta perspectiva, cobra sentido el análisis de la incidencia del contexto en la constitución de las subjetividades infantiles.

En referencia a la construcción mas mediática de la realidad, Lagos (2010) señala la escencialización de la infancia. Esa construcción encierra una lógica de naturalización del mundo y de la infancia esencializada, que conduce a la creencia de que los niños demandan consumir porque está en su propia naturaleza. Esa representación de la infancia niega el hecho de que, como postulan Rabello de Castro (1999) y Szulc (2006), los diversos modos de ser niños están estrechamente vinculados con los contextos en que se configuran experiencias de niñez y su mundo simbólico. En este sentido, sostenemos que, aun cuando los maestros se quejan constantemente de las prácticas de consumo de los niños a las que adjudican la falta de atención, la resistencia a la autoridad y la dificultad para incorporar normas y valores, la visión esencialista de la infancia, dominante en la escuela, resulta funcional a los intereses de la industria cultural infantil dominada por el mercado.

El modelo económico, político y cultural que se inició en la Argentina en 2003 generó condiciones de posibilidad de ruptura con la lógica mercantil dominanteen la década de 1990. En ese contexto, caracterizado por procesos de recuperación del Estado, en 2013 se aprobó el Diseño Curricular para la Educación Inicial de la Provincia del Chaco, elaborado por el conjunto de actores del sistema educativo (Directores de Niveles y Modalidades, Equipos Técnicos, Supervisores y docentes del Nivel).

De acuerdo con lo que establece el Art. 18 de la Ley de Educación Nacional $N^{\circ}$ 26.206/06, el Nivel Inicial está organizado en dos ciclos y constituye una unidad pedagógica que comprende a los/las niños/as entre los 45 días y los 5 años de edad inclusive, siendo obligatorio el último año. La letra de la Ley de Educación Nacional $\mathrm{N}^{\circ}$ 26.206 y las decisiones en materia de política educativa infantil en la última década tendieron a garantizar el derecho de todos los niños/as menores de 6 años a vivir una experiencia educativa desde edades tempranas. En esa línea, el Curriculum de Educación Inicial (en adelante CEI) incorporó enfoques y concepciones que quiebran tradiciones teóricas relativas a la El y la infancia. Pero en la dinámica entre la propuesta ajustada a la idea de la inclusión como función de la educación, y su construcción en la práctica, mediaron prácticas sociales de oposición a las políticas inclusivas desarrollas por el Estado. Hoy, ambas lógicas, la mercantil y la estatal -que reconoce la necesidad de construcción colectiva de la comunidad próxima y nacional-, 
conviven en las instituciones de todos los niveles del sistema educativo, en forma contradictoria y conflictiva.

\section{Marco de referencia}

La infancia ha sido un tema marginal dentro del campo de las ciencias sociales hasta la segunda mitad del siglo XX. Gracias a las reconceptualizaciones de la niñez, el campo de investigación sobre la infancia ha ido adquiriendo legitimidad y los niños comienzan a ser reconocidos como interlocutores válidos en la investigación.

Las políticas neoliberales de los '90, que implicaron la retirada del Estado como garante de los derechos sociales básicos, tuvo efectos excluyentes. Aun hoy no sólo existen deudas pendientes con respecto al cumplimiento efectivo del derecho a la educación, sino que se advierten al menos dos formas de pobreza derivadas de ese período: la que viven aquellos colectivos sociales que se encuentran en los márgenes del sistema, y la que viven sectores medios y medios bajos que han ido transitando progresivamente por el camino del empobrecimiento. Desde 2003, el rol más activo del Estado argentino produjo un cambio de rumbo de las políticas sociales y educativas y desarrolló políticas públicas inclusivas para la infancia, entre ellas, la ampliación de la educación inicial.

La comprensión del entramado en que se conjugan los procesos de transformación económica y sociocultural, nos permitirá comprender la incidencia de lo social en la construcción de las subjetividades infantiles, en particular, en el barrio Molina Punta de la ciudad de Resistencia, capital de la provincia del Chaco. El barrio está ubicado en avenida Laprida y calle 12, aproximadamente a 26 cuadras de la plaza central de la ciudad. No tiene límites muy claros. Su historia comienza con la toma de un terreno fiscal cercano al barrio Don Bosco, organizada por unas veinte familias con trabajos precarios y sin vivienda, a la que, de a poco, se fueron sumando otras, hasta superar las 40 familias. La toma del terreno exigió cierta organización para la distribución de la tierra, por lo que se fueron estableciéndolas medidas de los terrenos, calles y pasillos. La organización incipiente, fue creciendo hasta la constitución del Movimiento de Trabajadores Desocupados "La Favela"ii, a través de la cual los vecinos lograron visibilidad que los hizo beneficiarios de políticas públicas, desarrolladas por el Estado Nacional. Aproximadamente treinta familias forman parte del Movimiento, que sufre los avatares de la situación política provincial y las consecuencias de la herencia económica y cultural de los '90.

En el país, el acceso progresivo a la Educación Inicial a los 5 años, entre 2003 y2015, es producto de políticas para la infancia. Egido Gálvez (2000: 20) señala la complejidad del término educación inicial, que remite a conceptos relacionados, como el de infancia, susceptibles de interpretaciones en función de cada contexto. Señala asimismo la dificultad de establecer una diferenciación precisa entre educación inicial, educación preescolar o educación infantil, términos que alcanzaron mayor amplitud en los últimos años y abarcan hoy diversas modalidades de educación y aprendizaje destinadas a los niños desde las primeras semanas de vida hasta su ingreso en la escuela primaria.

Nuestro campo de interés es la educación inicial, entendida como el período de cuidado y educación de los niños, fuera del ámbito familiar, en los primeros años de su vida. De aquí la necesidad de tener en cuenta las diversas modalidades educativas, establecidas por ley, para niños desde el nacimiento hasta los 5 años de edad.

La metodología adoptada para el proyecto "Políticas públicas para la infancia: Incidencia de la obligatoriedad del Nivel Inicial en la construcción de la subjetividad de niñas y niños del barrio Molina Punta de Resistencia, Chaco", sigue una lógica cualitativa, que contribuye a la comprensión de la complejidad de un fenómeno social y los procesos intervinientes en él: la construcción de la subjetivad de niños y niñas. 
El diseño se encaró como estudio de caso. Este tipo de estudio favorece la comprensión profunda de una realidad singular, acerca de la que no sólo se informa sino que participa de un tipo de problemas, expectativas, imprevistos, conflictos, situaciones y hechos que la conforman. De aquí que la indagación se plantee como un estudio de caso instrumental (Stake, 1995). Interesa conocer el universo de los niños y niñas, para ver cómo los discursos que circulan en la comunidad y en la escuela, las situaciones en que esos discursos se inscriben y las experiencias infantiles, aparecen en sus dichos y cómo a través de ellos, sintetizan y construyen la relación con su mundo más inmediato: el Barrio Molina Punta. El universo de los niños y niñas estará constituido por diez niñas/os.

Para la indagación empírica, se apela a las voces de los niños y niñas, los padres y las maestras. Se tiene en cuenta también el juego y el dibujo, como modos de expresión simbólica. Como procedimiento para la indagación se utiliza la entrevista a niños y niñas, registrada a través de la forma en que se expresa el discurso que permite recuperar la voz, sin necesidad de encontrar traducciones de los significados, las experiencias e ideas expresados por los sujetos.

El trabajo se enmarca en el paradigma interpretativo, cuya característica principal es que posibilita descubrir los sentidos atribuidos a la realidad por los sujetos que intervienen en los procesos humanos. Se busca comprender las acciones discursivas y no discursivas de los sujetos, tratando de recuperar la subjetividad como construcción en un contexto histórico y social particular.

\section{Hipótesis}

La obligatoriedad del nivel inicial y la universalización de las salas de 3 y 4 años, como parte de las políticas públicas dirigidas a la inclusión, han permitido visibilizar una franja etaria dentro de la infancia, constituida por niños antes no escolarizados, que, a partir de su ingreso en la escuela, se incorporan al discurso de los padres, como sujetos de derechos.

\section{Preguntas problema}

¿Qué políticas públicas para la infancia desarrolla el Estado nacional?

¿A través de qué procesos sociales acceden las familias del barrio Molina Punta, a diversas políticas públicas para la infancia?

¿Qué experiencias de socialización viven niñas y niños del barrio Molina Punta?

¿Cómo se entraman esas experiencias de socialización con las experiencias vividas a partir de la escolarización en el Nivel Inicial?

¿Cómo se incorporan las niñas y los niños al discurso de los padres, a partir de la escolarización?

¿Qué características generales de las subjetividades infantiles del barrio Molina Punta es posible trazar? ¿Cómo incide el contexto en la construcción de esas subjetividades?

\section{Políticas de inclusión de niñas y niños (2003-2015)}

El inicio del siglo XXI coincidió con la crisis del neoliberalismo, consecuencia de su fracaso en todos los ámbitos y de la creciente toma de conciencia, por parte de distintos sectores de la sociedad, acerca del papel del mercado en la vida económica, social y cultural. Esa creciente toma de conciencia, reservada en los 90 a sectores minoritarios (sindicatos combativos, organizaciones de Derechos Humanos, pequeños grupos de intelectuales, organizaciones sociales y expresiones partidarias) significó un quiebre de la legitimidad del sistema y se tradujo en cambios de gobiernos en varios países de América Latina, a través de un viraje hacia la centroizquierda, que permitió el ascenso al poder político de líderes populares que desarrollaron políticas 
redistributivas e inclusivas, apoyadas en los principios de soberanía política, independencia económica y democracia no restringida a su carácter formaliii.

En Argentina, la crisis del 2001 , se convirtió en la antesala de una serie de cambios económicos, políticos y sociales, que a partir de 2003 se materializaron en políticas públicas de corte liberal, estatista y proteccionista. Barrera y Manzanelli (2015: 5-6) sostienen que con la asunción de Néstor Kirchner como presidente de la nación, se inicia en nuestro país la etapa de recuperación del Estado. Este primer ciclo de los gobiernos kirchneristas, se caracterizó por la primacía de lo "nacional" en las modificaciones del sistema económico. Las medidas económicas centradas en la interrupción de la subordinación de Argentina a los intereses del capital financiero y sus representantes políticos, los organismos internacionales de crédito, fueron acompañadas por medidas tendientes a romper con la lógica ideológica dominante desde la última dictadura. En ese contexto se desarrollaron políticas de inclusión de niñas y niños que se iniciaron en Argentina en el 2003.

Las políticas de inclusión se inscribieron, a su vez, en un conjunto de políticas de Derechos Humanos, que se iniciaron con la derogación, por parte del Presidente Kirchner, de las leyes de Punto Final y su complementaria, de Obediencia Debida, y la reapertura de los juicios por crímenes de lesa humanidad, cometidos durante la última dictadura cívico-militar, suspendidos después de las leyes de impunidad y el indulto de Menem (1989-1999), debido a la presión ejercida por los grupos económicos, los medios de comunicación hegemónicos, las fuerzas armadas y otros sectores conservadores del país. Precisamente, las políticas de inclusión y reducción de desigualdades, desarrolladas entre 2003 y 2015, se basaron en una nueva concepción de los Derechos Humanos, lo que en términos sociopolíticos significó su no restricción a la cuestión de los crímenes de lesa humanidad. Desde ese paradigma, se sancionaron leyes de reconocimiento de derechos de la infancia y la juventud, las mujeres y la familia, las comunidades indígenas, las personas migrantes, las identidades de género, las personas con discapacidad, el derecho a la comunicación, a la salud y la cultura. Asimismo, se impulsaron políticas contra la discriminación, la xenofobia y el racismo, y se desarrollaron programas que, con mayor o menor éxito, junto con las leyes que los sustentaban, formaron parte de la disputa simbólica y jurídica necesaria para legitimar el nuevo modelo económico-social. Según datos macroeconómicos de distintos organismos internacionales, debido a las políticas de inclusión, nuestro país se ubicó en el 2015, entre aquellos con nivel de pobreza crónica más bajos de la región, menor población bajo la línea de pobreza y mayor expectativa de vida y equidad en la distribución del ingreso. Entre 2004 y 2014, el crecimiento económico significó una expansión real del PBI de aproximadamente el $5 \%$ promedio anual, que se reflejó en todos los indicadores sociales. La inversión educativa se multiplicó casi por 20 veces en términos nominales (creció un $205 \%$ en términos reales). Y la educación argentina llegó a ser considerada una de las más avanzadas de América Latina, tanto con respecto a los resultados como a su carácter político-ideológico. Estos logros fueron reconocidos y destacados por UNESCO y UNICEF, entre otros organismosiv.

Las políticas económicas y socioeducativas de ese período, constituyeron un telón de fondo propicio para la reflexión sobre lo social en general, y sobre la niñez en particular. La lógica estatal logró permear parcialmente las prácticas discursivas y no discursivas dominantes en la escuela, aun fuertemente atravesada por la lógica mercantil.

Myriam Feldfeber y Nora Glutz (2011) destacan el cambio de rumbo de las políticas sociales y educativas de carácter inclusivo, implementadas desde 2003, basadas en un rol activo del Estado, que se materializaron, entre otras cosas, en políticas públicas para la infancia. Estas políticas atañen a dos planos: legislativo y simbólico. El primero contribuyó a un cambio de paradigma relativo a la concepción del 
Estado y sus funciones, así como a lo social, donde sin duda se juega la corresponsabilidad de gobernantes y agentes del Estado, entre los que está el docente. El Ministerio de Educación de la Nación entendía que "El Estado ha recuperado centralidad, legalidad y autoridad. En su carácter de regulador jurídicopolítico de la vida social, el Estado asume la función de conjugar intereses particulares y colectivos, lo que supone reconocer los derechos de los diversos colectivos sociales, sintetizados en un proyecto social. Ello, desde el presupuesto de que un Estado democrático presente, no delega en otros su rol. Por ende, define y orienta su acción política hacia la afirmación y profundización de los derechos de todos los habitantes del territorio nacional, reconociendo que las condiciones sociales en las que realiza su intervención están signadas por la desigual distribución de bienes materiales y culturales".

En materia educativa se sancionaron las siguientes leyes:

$\checkmark$ Ley de Garantía del salario docente y 180 días de clase ( $\left.N^{\circ} 25.864,2003\right)$,

$\checkmark$ Ley del Fondo Nacional de Incentivo Docente (N²5.919, 2004),

$\checkmark$ Ley de Educación Técnico Profesional $\left(N^{\circ} 26.058,2005\right)$,

$\checkmark$ Ley de Financiamiento Educativo (N²6.075, 2005)

$\checkmark$ Ley Nacional de Educación Sexual Integral $\left(N^{\circ} 26.150,2006\right)$,

$\checkmark$ Ley de Educación Nacional (N²6.206, 2006).

Se implementaron además, políticas tendientes a garantizar los derechos de las personas a la información y el acceso igualitario a la cultura. En esas políticas se inscriben la sanción de la Ley de Servicios de Comunicación Audiovisual (Ley № 26.522/09) en reemplazo de la ley de Medios de Comunicación de la última dictadura, la creación de los canales estatales ENCUENTRO y PAKA PAKA, y la restructuración de la TV Pública, medios que significaron un importante espacio de disputa ideológica con la cultura mercantil dominante.

En el marco de la adhesión de Argentina a pactos internacionales de Derechos Humanos y protección de la infancia y la adolescencia, se sancionaron leyes y se desarrollaron programas de protección de la infancia, la juventud, la familia y los adultos mayores. Entre otras se puede mencionar:

Protección Integral de los Derechos de las niñas, niños y adolescentes (Ley $N^{\circ}$ 26.061/2005).

-Programa Nacional de Salud Sexual y Reproductiva (Ley N²5.673/2002) y Programa Nacional de Educación Sexual Integral (Ley 26.150/2006).

-Ley de Migraciones (№ 25.871/04) reglamentada en 2010.

-Ley de Comunidades indígenas. Emergencia en materia de posesión y propiedad de tierras ( $\left.\mathrm{N}^{\circ} 26.160 / 2006\right)$.

-Ratificación de la Convención sobre los Derechos de las Personas con Discapacidad (Ley $N^{\circ}$ 26.378/2008).

-Ley de Identidad de Género ( $\left.\mathrm{N}^{\circ} 26.743 / 2012\right)$ y Ley de Matrimonio Igualitario $\left(\mathrm{N}^{\circ}\right.$ $26.618 / 10)$.

-Asignación Universal por Hijo (AUH), (Decreto Ley 1602/09).

-Ley Nacional de Protección Integral para prevenir, sancionar y erradicar la violencia contra las mujeres ( $\left.\mathrm{N}^{\circ} 26.485 / 2009\right)$.

-Ley 26364: Prevención y sanción de la trata de personas y atención a sus víctimas y Decreto 936, que prohíbe la publicación de avisos de comercio sexual, entre otras.

- Impulso de las políticas desarrolladas por el INADI (Instituto Nacional contra la Discriminación, la Xenofobia y el Racismo). 
La importancia de las reformas en el plano normativo, radican en que, como sostiene Bertranou (2011), el Estado representa un orden legal público de alcance universal, en la medida en que establece derechos y obligaciones que están por encima de la voluntad de los ciudadanos. En tanto orden legal, asegura (al menos en una primera instancia a través de las normas) derechos de ciudadanía para todos los habitantes.

La ciudadanía implica el derecho a integrar una comunidad en igualdad de condiciones. Al respecto, nos interesa recalcar que la responsabilidad individual de la construcción de lo comunitario es inherente a la integración activa de los sujetos (las personas) en una comunidad. Este señalamiento tiene para nosotros, el sentido de recalcar la importancia del papel activo del docente, en la construcción de la comunidad escolar y de la sociedad. En un Mensaje del Poder Ejecutivo del 3/09/14, puede leerse: "la educación de la primera infancia es más que nunca una obligación del Estado, como promotor, actor y garante, pero también es una responsabilidad de todos. Las familias y la comunidad en su conjunto deben coadyuvar en este esfuerzo colectivo para que la obligatoriedad de la educación cobre un sentido social pleno de compromiso con el destino de cientos de miles de niños y niñas que habitan nuestro país". (Ley $\mathrm{N}^{\circ} 27.045$, sobre la obligatoriedad de educación inicial para niños de 4 años).

En términos simbólicos, la legislación tendiente al reconocimiento de derechos, incidió en la construcción de nuevas identidades -que se configuraron a la par de la construcción de nuevas representaciones sobre "los otros"-, entre ellas, la de niñez, concebida en su carácter relacional.

\section{Política nacional de desarrollo y fortalecimiento de la EI}

En Argentina, con la sanción de la Ley de Educación Común № 1420 de 1884, que organizó la educación primaria, el nivel inicial fue contemplado como escuela especial de enseñanza primaria, no obligatoria. La Ley Federal de Educación $\left(\mathrm{N}^{\circ}\right.$ 24.195) promulgada en 1993, determinó la obligatoriedad de la $\mathrm{El}$, desde la sala de 5 años.

A partir de 2006, año en que entró en vigencia de la Ley de Educación Nacional № 26.206 y continuó el reordenamiento del sistema educativo que se inició en 2003 , el gobierno nacional impulsó la ampliación de la cobertura en la sala de 5 años. En 2014, a través de la Ley $\mathrm{N}^{\circ} 27.045$ sancionada por unanimidad por el Congreso de la Nación, se amplió el carácter obligatorio de la escolarización a partir de los cuatro años, a la vez que se les dio al Estado Nacional, a las 23 provincias y a la Ciudad Autónoma de Buenos Aires la responsabilidad de "universalizar los servicios educativos para los/as niños/as de tres años de edad, priorizando la atención educativa de los sectores menos favorecidos de la población”."(Ministerio de Educación de la Nación, 2015. Fortalecimiento y ampliación del derecho a la educación, pág. 48).

El fortalecimiento de la El implicó otras medidas fundamentales tomadas 0 impulsadas por el gobierno nacional:

$\checkmark$ Creación de la Dirección de Nivel Inicial en el Ministerio de Educación de la Nación y en casi todas las jurisdicciones educativas, en cumplimiento de los acuerdos federales iniciados en 2003.

$\checkmark$ Creación de cargos directivos, docentes y técnico-pedagógicos para el afianzamiento de esos nuevos organismos y la actualización de los diseños curriculares del nivel, que al 2015 se concretó en once jurisdicciones provinciales y se encontraba en proceso en otras nueve. 
$\checkmark$ Sanción de la Ley 27.064/2014, regulatoria del funcionamiento de los jardines maternales y de infantes no incluidos en la enseñanza oficial, que quedaron bajo la supervisión pedagógica de las autoridades educativas jurisdiccionales.

$\checkmark$ Distribución de equipamiento específico para el $\mathrm{NI}$ (44.793 ludotecas distribuidas de manera universal entre 2009/2015 en ámbitos rurales, urbanos, para salas de 0 a 5 años, únicas, itinerantes y multinivel; más de 8 millones de libros infantiles de 140.511 colecciones, y bibliotecas institucionales y de actualización pedagógica para docentes; 2.000 cajas de equipamiento para la enseñanza de las ciencias en todos los jardines de infantes de gestión estatal de las regiones NEA y NOA; láminas con fotografías de la fauna autóctona de todas las regiones, a 8766 jardines de infantes del país; materiales de desarrollo curricular de Educación Sexual Integral, Las abuelas nos cuentan, Cuadernos para el Aula, Cuadernos para el trabajo en sala multiedad, y la serie Temas de educación inicial que abarcan el juego, la literatura, la variedad de formatos institucionales y la historia del Nivel Inicial) (Idem, pág. 49)

$\checkmark$ Acciones para el desarrollo profesional docente (reforma de la Formación Docente inicial, llevada a cuatro años, con un giro en la concepción de la El como unidad pedagógica que educa a niñas/os entre 45 días y cinco años de edad, desde un abordaje pluridisciplinar; diversidad de propuestas de capacitación como Escuelas Itinerantes, Cátedra Nacional Virtual Abierta de Juego, Fortalecimiento de la educación inicial en el Ámbito Rural, Trayecto de Formación para Parejas Pedagógicas de la Educación Inicial en la Modalidad de Educación Intercultural Bilingüe, Encuentros regionales de maestros, Estrategia nacional Creciendo Juntos, Trayecto formativo para directivos. Se capacitaron 93.000 docentes y directivos sobre juego, indagación del ambiente natural y social, literatura, expresión corporal, relaciones entre la escuela y la familia, arte; 8.700 docentes cursaron la Especialización en Educación Maternal y otros 1.000 cursaron "Memoria, identidad y democracia en el Nivel Inicial". (Ibídem)

Estas acciones no tuvieron continuidad a partir de 2016.

A nivel nacional, según estudios de DINIECE (2010), la matrícula de NI mostró un comportamiento diferenciado según sala de 3, 4 o 5 años. Entre 1998-2009 la sala de tres años, con la menor cantidad de alumnos del nivel tuvo un crecimiento de la tasa de asistencia del $43,2 \%$, antes de finalizar el período. La sala de cuatro años creció el $60,1 \%$, (con el mayor incremento de matrícula en términos absolutos y porcentuales). Batiuk (2015) señala que en 2001, el crecimiento fue del $48 \%$ y en 2010 del $81,5 \%$. Esta tasa presenta diferencias a nivel de las provincias. En cuanto a inversión en infraestructura, entre 2001-2013 se construyeron 4213 salas de 3 y 9232 salas de 4 años.

La tendencia creciente de la matrícula se mantuvo hasta fines de 2015. En 2015, 418.980 niños no asistían al nivel inicial 3 a 5 años. De todos los niños mencionados, el $84 \%$ (350.731) habitaba en centro urbano. Del total de niños que no asistían, $73 \%$ (306.952) tenía 3 años, 22\% (90.565) tenía 4 años y 5\% tenía 5 años. (DiNIEE/SlyCE/ ME y DN en base a Relevamiento Anual 2014).

La relativa estabilidad de la matrícula en sala de 5 años, con oscilaciones de escasa magnitud, se debe a la amplia cobertura, mientras el pronunciado aumento de 
la sala de cuatro años se vincula con el mandato legal de la universalización (Ley $\mathrm{N}^{\circ}$ 27045).

Estos resultados autorizan a pensar que, de haber continuado el modelo políticoeconómico que se desarrolló entre 2003/2015, podía preverse similar movimiento de la matrícula, sobre todo, a partir del Decreto que universalizó la sala de tres años. Pero la asunción del presidente de derecha Mauricio Macri, modificó sustancialmente la situación antes descripta sobre la presencia y responsabilidad del Estado en materia de políticas socioeducativas.

Entre los 72 decretos firmados por el presidente Mauricio Macri, en los primeros doce días de gobierno, está el Decreto $\mathrm{N}^{\circ} 23$, a través del cual, redujo el presupuesto educativo del $6,5 \%$ del PBI al $3 \%$. A partir de ese momento, y desconociendo de la Ley de Financiamiento Educativo, el gobierno nacional avanzó en el desfinanciamiento de programas educativos (como Conectar Igualdad, Proyecto de Mejora Institucional, de Educación Sexual Integral, programas de formación docente, etc.) y la reducción del presupuesto universitario y de investigación. Estas decisiones en materia educativa se conjugan con medidas económicas y comunicacionales direccionadas a consolidar un modelo neoliberal en lo económico y neoconservador en lo social.

Las decisiones del gobierno nacional relativas a endeudamiento externo y trasferencia de ingresos a los sectores concentrados de la economía, incidieron en forma directa en un crecimiento abrupto de la pobreza, que en los primeros seis meses de gobierno produjo aproximadamente cinco millones de pobres más que la década anterior. Asimismo, la ruptura de la alianza política del gobierno argentino con los países de la UNASUR y su acercamiento a la Alianza para el Pacífico, se conjugan con gestos que se orientan a una nueva producción simbólica estatal que, a través del discurso de funcionarios de gobierno - entre los cuales están el ministro de educación y el presidente de la nación- subvierten la discursividad estatal construida en la década pasada, acerca de las personas como sujetos de derechos. El nuevo discurso conservador desvaloriza y demoniza a las personas migrantes, pobres, homosexuales y militantes de organizaciones y partidos políticos de oposición y reproduce el discurso dictatorial sobre el terrorismo de Estado y su estrategia de desaparición forzada de personas en la última dictadura cívico-militar. Entre tanto, el gobierno mantiene el discurso sobre la importancia de la educación inicial pero sin propuesta de financiamiento para su extensión. Mientras el nuevo esquema obligó a las provincias a tomar endeudamiento externo, el gobierno nacional las constriñe a responsabilizarse del financiamiento de las salas de 3 años, que prometiera en su campaña electoral. La cuestión de la cobertura de las salas de 3 y 4 años, se torna aún más problemática, debido al crecimiento de la desocupación, la baja del salario, el aumento abrupto de las tarifas de servicios básicos como agua y luz, y la retirada del Estado en materia socioeducativa.

Sin duda, el escenario actual plantea nuevos desafíos educativos para la atención de las infancias, que vuelven a ser vulneradas, ya sea por la posición de subalternación de amplios sectores de niñas y niños y sus familias o por el dominio de la lógica mercantil estatal actual, que los ubica siempre en posición de objetos.

\section{El currículum para la Educación Inicial de la provincia del Chaco}

El currículum para la Educación Inicial de la provincia del Chaco (CEI) se construyó con participación de docentes, gremios y padres, en foros y mesas de trabajo organizados por el Ministerio de Educación de la Provincia, para los niveles inicial, primario y secundario, durante el año 2012.

En esa circunstancia, la Dirección de Educación Inicial desempeñó un papel fundamental, corolario de acciones orientadas a la construcción curricular y la normativa para el nivel, que se venían desarrollando desde 2010, en mesas de trabajo 
con áreas técnicas del Ministerio de Educación de la Provincia, con el objeto de difundir las acciones realizadas y posibilitar que el futuro marco normativo jurisdiccional fuera producto de una construcción participativa y democrática de los docentes. En esa línea de trabajo, "... los Lineamientos Curriculares Generales para la Educación Bilingüe - Intercultural - Pueblos indígenas: Qom, Moqoit y Wichi, fueron elaborados por las comunidades indígenas a través de Foros." (CEI, pág. 19).

EI CEI se plasmó primero en una propuesta sometida a consulta a los docentes, en 2012, hasta su aprobación en 2013. En el Documento se explicitan nociones que configuran la concepción desde la cual el Estado asumió la educación inicial. A continuación, analizamos aquellas que aluden directamente a la infancia y la educación infantil inclusiva, reconceptualizadas a la luz de aportes de la antropología de la niñez, la historia de la educación, la pedagogía y el derecho, que fueron soporte de las políticas públicas.

La realidad da cuenta de diversos modos de ser niños. Para distintas disciplinas que hoy estudian la infancia, ésta es una categoría relacional, cultural e histórica, lo que exige pensar a niñas y niños en el entramado de relaciones que construyen con sus pares y con personas de distintas franjas etarias. El reconocimiento del carácter histórico-cultural de la noción de infancia, deviene en el reconocimiento de la existencia de infancias, o sea, de diversos modos de ser niños, estrechamente vinculados con los contextos en que se constituye la subjetividad y configuran experiencias de niñez y su mundo simbólico (Rabello de Castro, 2001; Szulc 2006).

Estos aportes conceptuales conducen a una reconceptualización de lo social y lo educativo. El reconocimiento de la existencia de infancias y de la producción social de lo subjetivo, se produjo - y se produce hoy- en el marco de tensiones y debates de carácter teórico y social. Esas tensiones o disputas se expresan en las prácticas y en los currículos escolares. Las prácticas se entienden como relaciones dialécticas entre los sujetos y las condiciones materiales y simbólicas- en que éstas se desarrollan. En ese entramado de relaciones dialécticas, se construyen también representaciones de la realidad. La representación dominante que sobre la niñez primó en los currículum escolares y de formación docente, hasta las reformas socioeducativas de la década pasada, inocenta la infancia y la universaliza como etapa a nostalgiar; concibe a los niños/as como seres frágiles, buenos, inocentes, caracterizados por la presencia del juego, incompletos, a ser formados y socializados por los adultos y coincide con las nociones de sentido común o con los abordajes de la psicología sobre el desarrollo infantil, señalados por Szulc (2006). Esa perspectiva de la infancia deja fuera del análisis a una diversidad de experiencias infantiles que no se ajustan a las definiciones teóricas sobre qué es ser niño.

El carácter relacional de la infancia, no impide, sin embargo, trazar algunas características de las infancias, considerando las determinaciones del contexto en que se configuran.

Desde la conformación del sistema educativo nacional (1884-1916c.), los niños de las clases altas tuvieron garantizada la educación temprana, mientras los niños de sectores medios y bajos debieron esperar definiciones del Estado, acerca de cuán merecedores de educación eran. Las disputas sociopolíticas y culturales de la época fueron determinantes de esa situación. En la actualidad, esas disputas no sólo no han desaparecido, sino que se expresan a través de tensiones y conflictos en las prácticas escolares, incluso a veces de forma velada, a través de especulaciones de carácter pedagógico. Al respecto, Malajovich (2006) habla de "viejas contradicciones del nivel Inicial", tales como niño responsabilidad exclusiva de la familia vs niños responsabilidad de la sociedad; rol de la familia en la educación de los hijos vs papel del Estado en la educación; iniciativa privada vs responsabilidad del Estado; mujer productora vs mujer reproductora; rol tradicional de la mujer como principal responsable de la tarea de educar a sus hijos vs rol del nivel inicial en esa tarea. 
Como señala Carli (2002), en Argentina, recién con el Estado de Bienestar, en la etapa peronista (1945-1955), la infancia adquirió visibilidad como sujeto de políticas públicas.

Pero la crisis de ese Estado en los 70, consecuencia de cambios en las relaciones económicas y geopolíticas internacionales, agilizó la aplicación de políticas neoliberales y neoconservadoras, en todos los ámbitos, las que requirieron para su legitimación, de la construcción de un imaginario social correlativo del sistema económico. El escenario neoliberal que se inició con la última dictadura cívico-militar (1976-1983) y se consolidó en los '90, se caracterizó por la concentración económica, la distribución regresiva del ingreso, la desocupación y la precarización laboral, el crecimiento de la pobreza y la desigualdad. Todo ello contribuyó a la profundización de la fragmentación social y la marginación de amplios sectores que quedaron excluidos del acceso a derechos sociales básicos como la educación. Carli (2006) plantea que en este contexto, la niñez devino en un laboratorio social, y constituyó un espacio de profundas mutaciones, de nuevas pautas de socialización y políticas de crianza. El desempleo, la movilidad descendente y la pobreza, profundizaron la brecha entre niños pertenecientes a familias en condiciones de trazar un horizonte de futuro y niños que padecían las consecuencias de políticas fundadas en la producción de la desigualdad. En toda la década, primó una perspectiva sesgada de los niños, que resultó en una "patologización de la infancia". Esa perspectiva se apoya en meros supuestos ideológicos, que a través de la distorsión de enunciados provenientes del campo de la psicología, son convertidos en parámetros universales de "niñez", "civilización", "educabilidad", "adaptabilidad" y "humanidad". Sobre la base de esos parámetros, se establecen criterios de "normalidad", categoría desde la cual se describe y se juzga a los niños por la religión que profesan, su identidad sexual o étnica y su procedencia de clase, y se desarrollan prácticas de adiestramiento para el disciplinamiento, primero escolar y luego social. Sobre la base de juicios morales basados en prejuicios- se castigan determinadas formas pensar, de hablar, de comportarse; en definitiva, formas de ser. Y se actúa para "corregir" aquellas conductas consideradas "desviadas" cuando no responden a los parámetros dominantes sobre los que se establece qué es lo "normal", lo "adecuado", lo "correcto".

La concepción de educación inicial está en estrecha dependencia de la noción de infancia. De hecho, resulta complejo establecer una diferenciación precisa entre educación inicial, educación preescolar y educación infantil. En la década pasada, la ampliación de estos conceptos condujo a la consideración de diversas modalidades de educación y aprendizaje destinadas a niñas y niños desde las primeras semanas de vida hasta los seis años de edad. Para Egido Gálvez, (2000), la educación inicial comprende una diversidad de prácticas y sistemas de atención a la infancia. En esta línea, el Curriculum para la Educación Inicial incluye las modalidades de educación bilingüe intercultural, rural, en contexto de encierro, especial, hospitalaria, y domiciliaria, en la El, y las entiende como instancias que "atraviesan y fortalecen el proceso de inclusión y respeto por la diversidad, generando verdadera igualdad de oportunidades".(CEI, pág. 16.)Con respecto a la atención de niñas y niños en cada caso, el CEI remite a las leyes inclusivas no educativas antes mencionadas.

El apartado del CEI, referido a los marcos normativos, se inicia con el reconocimiento explícito de los niños como sujetos de derechos y de la Convención Internacional sobre los Derechos del Niño, considerada Ley Suprema para la infancia y referencia obligada para "... la revisión de todos los marcos normativos y la inclusión de la niñez en los mismos, la definición de líneas tendientes a la organización e implementación de planes, programas y proyectos destinados a la efectivización de los derechos del niño" (pág. 25). Continúa con una descripción de los alcances de la Ley $N^{\circ} 26.061 / 2005$, y recupera los principios de la CIDN, en los Fines y objetivos de la política educativa provincial. 
La CIDN, a la que Argentina adhiere desde 1989, a través de la Ley $N^{\circ} 23.849$, contribuyó significativamente a modificar la representación de la infancia, al reivindicar el carácter de sujetos de derecho de niños y niñas y reconocer la capacidad de aprendizaje en sus primeros años de vida, así como la existencia de nuevas configuraciones familiares y los cambios del rol de la mujer en la sociedad: "En este caso se trata de romper con viejas estructuras naturalizadas de una infancia feliz y libre de problemas y dificultades, para plantear una atención educativa desde las oportunidades que cada una de ellas tiene, brindando igualdades lúdicas y educativas a toda la infancia, recordando que los niños son sujetos de derecho más allá de lo que su contexto o su realidad le ofrece. Realidades atravesadas por dificultades físicas, legales, con barreras físicas, culturales, entre otras". (CEI, pág. 40).

La ruptura con el supuesto de la infancia feliz, tiene al menos dos implicancias.

Por un lado, significa una superación del psicologismo que, sin abandonar los aportes de las diversas corrientes psicológicas al campo de la educación de las infancias, abre la mirada hacia lo social en varios sentidos:

a) La consideración de los aspectos sociales constitutivos del sujeto, obliga a los educadores a dislocar la mirada centrada exclusivamente en las niñas y los niños, y dirigirla a conocer y problematizar los acontecimientos sociales, económicos, políticos y culturales que configuran el mundo material y simbólico en general, y no tan solo el "mundo infantil".

b) La advertencia por parte de los docentes, de las determinaciones contextuales que inciden en la propia constitución y trayectoria de formación, lo que lo ubica así muy lejos de ser el portador de la verdad y "los valores correctos".

Por otra parte, significa un desafío pedagógico, que pone en juego la necesidad de concertación y creación colectivas a la hora de tomar decisiones sobre qué y cómo enseñar, para incluir a la diversidad de niñas y niños que habitan las escuelas.

La Ley de Educación Nacional sancionada en 2006, ratifica el valor sustantivo de la primera infancia para la historia de los sujetos en sociedad y propone la obligatoriedad del nivel. Estas definiciones incidieron en la modificación de los propósitos de la El, la incorporación de nuevos contenidos y campos de conocimiento, la revisión de los sentidos de la formación docente y de las condiciones materiales y simbólicas que operan en la construcción de la identidad del nivel. "Este Documento Curricular, que reconoce la heterogeneidad, las diversidades culturales, étnicas y lingüísticas, aborda una conceptualización frente a la concepción de la nueva infancia que debe definir los marcos curriculares... y... organizar el sentido de los aprendizajes en la franja de 0 a 5 años. Los cuatro pilares fundamentales: aprender a conocer, aprender a hacer, aprender a vivir juntos y aprender a ser, definen el propósito de la Educación Inicial favoreciendo la construcción de ciudadanía, recuperando los valores de la cultura en cada ámbito y la consideración plural de la infancia, legitimando diferentes contextos de crianza y tradiciones, complementando la labor educativa de las familias" (CEI, pág. 16).

EI CEI reconoce la conformación de una matriz sociocultural diversa del territorio provincial, cuyo origen fundacional se remonta a los asentamientos de las poblaciones Qom, Moqoit y Wichi, a la que se suma luego población migrante, primero de Paraguay y de la provincia de Corrientes y luego de una Europa en situación de crisis política y económica. Se reconoce explícitamente que los pobladores originarios se vieron "obligados a enfrentamientos y resistencias de manera muy violenta,... en una lucha desigual, producto de la conquista del territorio, como, por ejemplo, la Masacre de Napalpí, donde... fueron avasallados y prácticamente exterminados, lo cual no fue una matanza aislada, sino una práctica recurrente del poder político y los terratenientes - con la mano de obra policial o militar- para privar a los pobladores originarios de su forma ancestral de vida e introducirlos por la fuerza al sistema de producción" (CEI, pág. 30).Señala como otra consecuencia negativa de la conquista, 
"la pérdida de la riqueza cultural, sistematizando una enculturación, que devino en el menoscabo de sus tradiciones, lengua madre y costumbres de crianza" (CEI, pág. 31).Reconoce, finalmente el aporte de las comunidades indígenas y migrantes a la riqueza cultural y social de la provincia.

La significatividad de la explicitación de estos elementos, radica precisamente en que su nombramiento posibilita una ruptura con la concepción etnocéntrica que clasifica los sujetos sociales en términos de civilizados- incivilizados, dicotomía coherente con la matriz cultural racista, que se configuró como consecuencia de los procesos de conquista por parte de Europa y la raíz oligárquica liberal del sistema educativo nacional. La noción supone, finalmente, el reconocimiento de la existencia de infancias.

Por otra parte, al reconocer el origen político de la situación actual de los pueblos indígenas, el CEI reafirma el carácter político de la educación, con lo que traza un horizonte desde el cual pensar los fines de la educación y la función social del docente como agente de un Estado democrático, que reconociendo la diversidad como riqueza, no persiga la uniformización/homogenización, sino la inclusión en la diversidad.

No es de extrañar, entonces, que estos principios, que tensionan aquellos sobre los que se fundó el sistema educativo nacional, y el jardín de infantes en particular, sean resistidos, aún hoy, en los discursos y prácticas educativas. Lo mismo ocurre con el principio social de la inclusión, como rector de la educación pública plasmado en las Leyes de Educación Nacional y Provincial y en los documentos emanados de acuerdos federales de la década en que se efectivizaron en políticas públicas. Aunque hay que reconocer que en el Nivel Inicial, este principio generó menos resistencia que en los otros niveles del sistema educativo, en los que priman el principio de la selección -identificado con calidad educativa- y la oposición a las políticas inclusivas, bajo la falacia de que con la inclusión el gobierno promovía el facilismo y perseguía la mera aprobación de todos los estudiantes. Sin embargo, si bien el Nivel Inicial tiene una larga tradición de inclusión en términos de matrícula en la sala de 5 años, en la práctica, ésta se ve muchas veces reducida a la asistencia de los niños y las niñas al jardín; donde aún persisten prácticas que, fundadas en concepciones androcéntricas y etnocéntricas, tienden a disciplinar y corregir identidades, gustos, deseos y formas culturales de construcción de los conocimientos y de lo social.

Las cuestiones antes señaladas se advierten en un currículum que evidencia que, en la conformación de las subjetividades docentes, perdura cierto divorcio entre la teoría y la práctica, entre las concepciones teóricas que muestran caminos para la construcción de una escuela inclusiva y democrática y las concepciones docentes naturalizadas con respecto a la familia, la infancia, la función social de la educación, etc. Estas concepciones y representaciones se fundan no siempre en teorías perimidas o prácticas tradicionales, sino también en meras opiniones docentes, producto de efectivos mecanismos de inculcación ideológica con que cuentan el mercado y otras instituciones no estatales que realizan acciones políticas de promoción de valores conservadores. Por ello, en muchos jardines de la provincia del Chaco, hoy se obliga a niñas y niños a rezar según cánones de la fe católica, se orienta el juego y se corrigen conductas y modos de ser según diferencias de género de la tradición patriarcal, y se promueve el consumismo a través de la orientación del gusto estético según cánones de la cultura dominante. Con respecto a esta última, por ejemplo, es común la presencia de la figura de Papá Noel en los actos de cierre del ciclo lectivo.

Por otra parte, en los apartados del CEI que se refieren a cómo aprenden los niños en el jardín, priman fundamentos psicológicos, y la didáctica del nivel se enuncia sin vinculación alguna con fundamentos sociopolíticos requeridos para asumir el quehacer docente en consonancia con los principios éticos y jurídicos promovidos por las políticas públicas inclusivas de la década pasada en nuestro país. Aun cuando los 
autores de referencia mencionados en el CEI puedan ser ubicados en alguna perspectiva teórica de ruptura con la tradición dominante, se recortan párrafos según criterios que lavan el discurso teórico despojándolo de su contenido político. El CEI resulta así un documento en el que los principios ético-jurídicos universales de la atención a las infancias aparecen enunciados en forma fragmentada con respecto a la vida escolar, los contenidos y la enseñanza.

En el período 2003/2015, en la provincia del Chaco, la matrícula en salas de 3 y 4 años, presentó un crecimiento del $10,9 \%$ y del 59,2\%, respectivamente, mientras la sala de 5 años se mantuvo en el $88,8 \%$ de escolarización en igual período. La expansión de las salas de 3 a 5 años, constituye un indicador de los procesos de democratización que, en la década pasada, se materializaron en políticas públicas. El crecimiento no fue igual en todas las jurisdicciones, pero sí continuo. Ahora bien, la cobertura de la sala de 5 años en la provincia, alcanza las zonas urbanas, de aquí la necesidad, tanto de garantizar la educación inicial en zonas rurales, como la formación profesional necesaria para responder a una demanda que es hoy, obligación jurídica y moral, sin olvidar que esta modalidad se inscribe en las particularidades y complejidad de la vida rural, a la que se le suman situaciones burocráticas propias de la administración escolar en esos contextos, por lo que requiere un análisis particular. Aun así, en contextos rurales de la provincia, es posible reconocer modelos organizacionales como plurisalas. Aunque éstas existen también en Escuelas de Gestión Social de la provinciavi, y no solo no constituyen una novedad en el sistema educativo nacional, sino que en el NI caracterizó los jardines de infantes urbanos en la década de 1990, cuando la matrícula disminuía año a año como consecuencia de la pobreza y la desocupación. Al respecto, es necesario señalar que, a partir de la Ley de Educación Nacional, la atención en plurisalas de la El implica por un lado, una forma de agrupamiento y, por otra parte, un modo de intervención docente.

A propósito de la cuestión de la función educadora de la familia vs responsabilidad del Estado, señalada por Malajovich (2006) como tensión, en el CEI su expresa claramente que es el Estado, el principal responsable de esa función, que debe ser acompañada por las familias. Estas consideraciones constituyen aportes fundamentales para romper con prácticas culpabilizantes de los niños y sus familias, que persisten hoy en todos los niveles del sistema educativo formal. Asimismo, ponen en evidencia la importancia de la recuperación del Estado en la construcción de lo simbólico y lo social. En consonancia con la lógica estatal inclusiva, en la página 70, el $\mathrm{CEI}$ se refiere a esa noción del siguiente modo: "En la actualidad, las nuevas y variadas configuraciones familiares, se van construyendo no solo entre la diversidad sino también, en las desiguales condiciones materiales y simbólicas de vida. En este sentido, hablamos de familias y no de la familia. Es por ello que en estas nuevas clasificaciones, según la diversidad de configuraciones se encuentran: familias monoparentales, familias nucleares, familias ampliadas 0 extendidas, familias ensambladas, de hogares sustitutos, adoptivos, de parejas homosexuales, etc..." No escapa a nuestras consideraciones, sin embargo, que a pesar del reconocimiento de la necesidad de "...instalar la mirada del conflicto, redefiniendo el propio sentido simbólico y material de las diferencias, desde el sentido histórico de las mismas y las relaciones de poder que en ellas se juegan." (CEI, pág.70), todavía abundan prácticas reproductoras de un modelo único de familia, impulsadas por grupos de poder con un particular interés en la defensa de un modelo social conservador, que se ve amenazado ante cualquier política de ampliación de derechos. En este sentido, resulta valioso el reconocimiento de que "Si bien éste es un contenido que no forma parte de la formación inicial en la carrera docente, en sí mismo se torna un tema que se aborda cotidianamente más desde el sentido común, desde la propia experiencia del docente con su entorno, que desde una cuestión previamente planificada e incluida dentro de los proyectos institucionales" (CEI, pág. 70). Al respecto, las teorías de la reproducción 
social han demostrado suficientemente las nefastas consecuencias sociales que encierra la creencia en el presupuesto del sentido común y de la posibilidad de abordar esos contenidos desde la propia experiencia del docente con su entorno, pues precisamente muchas de las ideas provenientes de un supuesto sentido común -y en tanto "común", representado como incuestionable-, se han convertido en principios legitimadores de prácticas racistas y discriminatorias. Como señala Bourdieu (2002), el sentido común no existe, es el menos común de los sentidos, pues es, en definitiva, un sentido instalado por las clases dominantes. Por otra parte, el enunciado encierra cierta naturalización de la ausencia de la temática en la formación docente, lo que implica un menoscabo del conocimiento de lo social. Ello nos autoriza a suponer que, en lo que se da en llamar "la especificidad del nivel" persisten aún elementos de la concepción psicologista de la educación que centra la mirada en el individuo, sin consideración de los procesos económicos y socioculturales en que tal noción de la modernidad se gestó y consolidó. Por otra parte, no podemos dejar de señalar, que tales expresiones se inscriben como demanda social a las instituciones de formación de docentes para el nivel.

En el punto 5 del CEl, referido a esa cuestión, la relación familias-institución, está expresada a través de preguntas "dilemáticas" sobre las acciones que debe emprender el docente con respecto a la participación de los padres en la educación de sus hijos: "Esta cuestión encierra un dilema, incluimos a los padres como... (educandos) y planificamos para ellos, o los colocamos a la par nuestra y les pedimos que aúnen criterios con nosotros? ¿En el primer caso, los igualamos al niño? ¿En el segundo, les demandamos una racionalidad que a lo mejor no pueden tener (Fairestein, G. 2005)?".

La incorporación de estas preguntas, remiten a un posicionamiento docente fundado en principios ilustrados que conducen a una representación de la escuela como poseedora de una única racionalidad aceptable y único lugar legítimo para la transmisión de conocimientos y normas. En vez de tan categóricas afirmaciones, resultaría pertinente y valioso formularse preguntas que tiendan a una verdadera reflexión sobre la construcción de lo social, lo que exige asumir la co-responsabilidad de padres y docentes, no sólo en su condición de tales, sino principalmente como sujetos éticos y políticos. Ese es el lugar, que invita a ocupar un Estado verdaderamente democrático.

Con respecto al desempeño docente, el CEI recupera las definiciones nacionales relativas al docente como agente del Estado. Estas definiciones constituyeron el eje del discurso político sobre la educación y del Programa Nacional de Formación Permanente NUESTRA ESCUELA, del Ministerio de Educación de la Nación ${ }^{\text {vii }}$. La relevancia de ese concepto devino de la necesidad de reinstalar el compromiso profesional, en un colectivo que sufrió directamente las consecuencias del modelo neoliberal de la década anterior (fragmentación del sistema educativo nacional, desjerarquización de la profesión, bajos salarios que en algunas jurisdicciones llegaron a ubicar a miles de docentes bajo la línea de pobreza, y condiciones de trabajo precarias). El documento señala que "La sola publicación y difusión de esta Propuesta Curricular..., no garantiza más y mejores aprendizajes, será cada Docente, Directivo y Supervisor, quien desde el análisis, resignificación, compromiso y pasión por la tarea, lo hará posible" (CEI, p. 16) y define el desempeño en los siguientes términos: "El rol del educador en instituciones de Educación Inicial es una construcción política, social, cultural y pedagógica que se da en un contexto de espacio y tiempo determinado, que se basa específicamente en el trabajo con el otro,... interdisciplinario, en la reflexión permanente, además de ponerse en el lugar del otro, poner el cuerpo, apoyar, recibir, acoger, sostener, contener, cooperar, gestionar, crear un vínculo fundado en el afecto y respeto hacia el/la niño/a, como pilares fundamentales de la acción profesional en la concreción de la garantía de los Derechos del Niño en cada uno de los ámbitos 
sociales e institucionales en los que se encuentran los niños y sus familias." (CEI, pág. 66). En el primer enunciado se apela al compromiso docente en la construcción de una educación eficaz, lo que lo ubica en una posición social activa. En el segundo, se reconoce explícitamente el carácter ético-político y sociocultural de las prácticas docentes, mientras se mantiene la categoría de rol-propia de la tradición liberal-, que concibe el desempeño como una función fija, establecida por el sistema social como organismo incuestionable de distribución de papeles sociales según criterios económicos.

\section{Conclusiones}

El análisis del CEI contribuyó, en primer lugar, a pensar los sentidos de los debates en torno a la función de la educación inicial en Argentina en los últimos años, particularmente en la provincia del Chaco. Esto cobra relevancia en tanto, en nuestro país, el dominio de la matriz fundante de la El, generadora de prácticas docentes estereotipadas, devino en un escenario en que el debate sobre la función social del nivel fue escaso.

Recién en los últimos treinta años, con el fortalecimiento de los gobiernos constitucionales, en Argentina se fueron incorporando progresivamente a la EI, los/as niños/as de sectores vulnerados en el derecho social a la educación. Los procesos de democratización social, implicaron mayor democratización en el acceso a la educación; las tazas de matriculación se vieron progresivamente en aumento, producto de la legislación vigente con respecto a la obligatoriedad de escolarización de los niños de 5 años y la universalización de la sala de 4 años, respectivamente. La educación temprana de niños y niñas, contribuyó a su incorporación al discurso social, como sujetos de derechos.

Esos procesos no fueron ajenos a los debates internacionales y a los cambios paradigmáticos de nociones implicadas en la educación de las infancias, que significaron avances en cuanto a posibilidad de pasar de un paradigma de tutelaje a otro de reconocimiento de niños y niñas como sujetos de derecho.

EI NI tiene una función pedagógica, pero también una función política, pues es la puerta de entrada de niños y niñas al sistema educativo, pero también al acceso a derechos y oportunidades presentes y futuras, no sólo para éstos, sino también para las familias, que, a través de los niños, autorizados en su condición de sujetos, pueden incorporar concepciones que contribuyen a la construcción social, atendiendo las demandas infantiles, que a veces se oponen a la lógica dominante.

El currículum resulta así una herramienta indispensable para instalar no sólo nuevos temas, sino también nuevas concepciones y formas de organización del trabajo en los jardines, orientadas por perspectivas que, teniendo como horizonte las transformaciones económico-políticas y socio-culturales producidas en la última década por los gobiernos nacionales de América del Sur, contribuyan ala inclusión, el fortalecimiento del pacto social y a la construcción de un imaginario de emancipación, condición necesaria para el desarrollo soberano de los países de la región.

Desde una mirada ética del currículum, Connell(1997) nos invita a pensar desde la categoría de justicia curricular. Al respecto, enuncia tres principios del diseño de un curriculum que conduzca a la justicia social:

1. Los intereses de los menos favorecidos, 2. Participación y escolarización común, y 3. La producción histórica de la igualdad.

La concreción de esos principios requiere de un posicionamiento ético de los docentes, capaz tanto de reconocer la conflictividad inherente a lo social, como de producir un currículum contrahegemónico, en una clara apuesta por la transformación social en términos humanitarios.

Un currículum de esta naturaleza, se funda en la idea de que la educación debe servir específicamente a los intereses de los menos favorecidos, encarando la 
enseñanza desde la situación de los pobres, y no de los ricos, desde la posición de las mujeres, de los indígenas, de los negros, de los homosexuales, y así sucesivamente. La apuesta por la transformación social así entendida, resulta, para Connell, un juego dialéctico entre la atención a las necesidades de los sectores menos favorecidos y el enriquecimiento de la experiencia y los conocimientos de los grupos favorecidos.

Desde esa lógica, las prácticas docentes, deben orientarse a:

- Promover prácticas cooperativas que posibiliten la toma de decisiones colectivas sobre cuestiones trascendentes para la democracia participativa, la que se define por el hecho de que todos los ciudadanos tienen, en principio, la misma voz. Esta es la base de un currículum común, construido "como una cuestión de justicia social".

- Poner a disposición de los estudiantes la parte generalizable del currículum tradicional, y garantizar a todos, el acceso a la diversidad de métodos, descubrimientos científicos y habilidades para la apropiación de nuevos conocimientos.

- Producir igualdad, asumiendo que ésta, al igual que las relaciones sociales en que se funda, es una producción histórica.

Connell señala asimismo la necesidad de que los docentes, en posición de producir igualdad, participen de experiencias no escolares, orientadas a ese fin. La importancia de este señalamiento radica, para nosotros, en que, el reconocimiento del otro como sujeto de derechos, se construye en las experiencias compartidas con la otredad.

La tarea docente, así concebida, requiere asumir las prácticas en el campo educativo, dentro de un sub-campo: el del trabajo docente, lo que en el sentido bourdiano del término, significa asumirlas desde la lógica de un campo social, que lo hace aparecer como resultado de un interjuego con otros campos, de los cuales no sólo se diferencia y recorta, sino también se nutre.

El Jardín de Infantes surgió en siglo XIX y se expandió en XX con una forma institucionalizada para educar a la infancia urbana y de clase media. Ese mandato fundacional, fue largamente cuestionado por movimientos sociales y comunidades indígenas de nuestro país, que vienen exigiendo la modificación del "formato escolar" de la educación inicial, expresado en el Curriculum para la Educación Inicial de la Provincia del Chaco.

A pesar de las deudas sociales y de las contradicciones de la educación inicial, es innegable que, en Argentina, las políticas públicas de reconocimiento de derechos de las infancias y de fortalecimiento de la educación infantil, han alcanzado alto nivel de consenso social y han contribuido a la construcción de un ethos social más sensible con respecto a la niñez. Sin embargo, no se debe negar el hecho de que a nivel mundial, se multiplican hoy las formas del racismo, que se expresan en el triunfo de opciones políticas de derecha que culpabilizan a los menos favorecidos del fracaso de las medidas económicas que los sectores conservadores aplican.

Esto explica en parte, por qué, a medida que el Nivel Inicial va alcanzando mayor legitimidad en nuestro país, crecen también las tensiones relativas a la función del nivel, y se reeditan viejos conflictos sobre su función y sentido. Estos conflictos, que atraviesan la formación docente, despotencian el nivel y contribuyen a legitimar la representación ingenua y banal del jardín de infantes como mero lugar donde depositar a los niños pertenecientes a los sectores medios y altos de la sociedad.

La revisión de los sentidos y mandatos de origen del $\mathrm{NI}$ y de cada uno de los niveles de la educación obligatoria, constituyen hoy, en Argentina, un gran desafío, en un contexto social permeado por un discurso y una política gubernamental, orientados a profundizar la conflictividad social, a través de la culpabilización del otro (pobre, indígena, homosexual, disidente).

Posicionados los docentes en el lugar asignado por la tradición, difícilmente 
podamos hacer frente al aparato estatal y del mercado, que se despliega a través de los medios de comunicación de masas, para la transmisión de una cultura vulgarizada por el interés del lucro. Peor aún, la asunción de una postura pretendidamente aséptica - aunque no por ello ingenua - frente al conocimiento, la historia y la sociedad, conduce a la inacción, apoyada en la opinión reduccionista de que "el mundo siempre fue así y los maestros no podemos hacer nada".

Es necesario pues, reconocer la estrecha relación entre las trayectorias de formación de los docentes y el contexto histórico. Pues en la formación profesional inciden las representaciones sociales dominantes y no dominantes en estrecha dependencia de los procesos históricos que posibilitan o restringen, tanto la circulación de teorías y cosmovisiones, como la vivencia de experiencias alternativas y creadoras. La política económica y socioeducativa que lleva adelante el actual gobierno nacional, no sólo ofrece escasas posibilidades de creación, sino que la condena. Al mismo tiempo, en la dialéctica de lo social radica la oportunidad para la transformación del estado de cosas.

\section{Bibliografía}

Aguado. J.C. y Portal, A.M. (1991) Tiempo, espacio e identidad social. Alteridades. México: Universidad Autónoma Metropolitana Unidad Iztapalapa. ISNN: 0188-7017.

Apple, M. W. "El neoliberalismo y la naturalización de las desigualdades sociales". En: Apple, M. W., Da Silva, T. T. y Gentili, P. (1997) Cultura, política y currículo. Buenos Aires: Losada.

Barrera, M. y Manzanelli, P. La naturaleza política y la trayectoria económica de los gobiernos kirchneristas. Cuadernos de Trabajo $N^{\circ}$ 14. CIFRA-CTA. Buenos Aires, Octubre de 2015.

Batallán, G. y Campanini, S. (1990) "El "respeto a la diversidad" en la escuela: atolladeros del relativismo cultural como principio moral". En: Jociles, M. I., Franze, A. (Eds.) ¿Es la escuela el problema? Perspectivas socio-antropológicas de etnografía y educación: Madrid: Taurus.

Batiuk, V. y Coria, J. (2015) Las oportunidades educativas en el Nivel Inicial en Argentina: aportes para mejorar la enseñanza. Buenos Aires: OEI-UNICEF.

Bertranou, J. (2001), "El desempeño del gobierno. Análisis de los aportes a la definición teórica de los conceptos", Revista Política y Gestión, Vol. 2, Buenos Aires.

Bourdieu, P; Chamboredon, J.C. y Passeron, J.C. (2002) El oficio de sociólogo. Presupuestos epistemológicos, Buenos Aires: Siglo XXI.

Bustelo Graffigna, E. (San Juan, Argentina) El "Mundo Disney" es una fábrica de consumidores.Terra Magazine. Revista Digital. 13 de septiembre de 2007.

Carli, S. (comp) (2006). La cuestión de la infancia. Entre la escuela, la calle y el shopping. Buenos Aires: Paidós.

Carli, S. (2002) Niñez, pedagogía y política. Transformaciones de los discursos acerca de la infancia en la historia de la educación argentina entre 1880 y 1955. Buenos Aires: Miño y Dávila, $1^{\circ}$ ed.

Cohn, C. (2005) Antropologia da criança. Rio de Janeiro: Jorge Zahar editor.

Colangeló, M. A. (2003) La mirada antropológica sobre la infancia. Reflexiones y perspectivas de abordaje. Ministerio de Educación de la Nación, 28 de noviembre de 2003.

Publicación

on-line: www.me.gov.ar/curriform/publica/oei 20031128/ponencia colangelo.pdf

EgidoGálvez, I. (2000) EGIDO GÁLVEZ Inmaculada "La educación inicial en el ámbito internacional: situación y perspectivas en Iberoamérica y en Europa”. En: Revista Iberoamericana de Educación, № 22, Monográfico: Educación Inicial, eneroabril, Madrid, Organización de Estados Iberoamericanos (OEI). 
Feldfeber, M. y Glutz, N. (2011) "Las políticas educativas en Argentina: herencias de los '90, contradicciones y tendencias de 'nuevo signo'". Revista Educação\&Sociedade vol. 32 n. 115, CEDES, Campinas, San Pablo, abril/junio de 2011. Disponible en www.scielo.br/pdf/es/v32n115/v32n115a06.pdf

Frigerio, G. y Dicker, G. (2005) Educar, ese acto político. Buenos Aires. Editorial del Estante.

Gentili, P. (2007) Desencanto y utopía. La educación en el laberinto de los nuevos tiempos. Rosario: Homo Sapiens Ediciones.

Giroux, H. (2003) La inocencia robada. Juventud, multinacionales y política cultural. Madrid: Morata.

Lagos, L. (2010) "La Generación Superpoderosa". Revista Margen N 59. Edición primavera. Consumo cultural y subjetividades massmediáticas: el lugar de las infancias y las juventudes.

Mc Laren, P. (1998) Pedagogía, identidad y poder, Santa Fe: Homo Sapiens.

Malajovich, A. (2006) Experiencias y reflexiones sobre la educación inicial. Una mirada latinoamericana, Buenos Aires: Siglo XXI.

Rabello de Castro, L. (2001) "Introducción: Infancia y adolescencia hoy". En: Infancia y adolescencia en la cultura del consumo. Buenos Aires: Grupo Editorial Lumen Humanitas.

Szulc, A. (2006) "Antropología y Niñez: De la omisión a las culturas infantiles". En: Wilde, G. y Schawmber, P. (eds.) Culturas, comunidades y procesos contemporáneos. Buenos Aires: Editorial SB.

Ministerio de Educación de la Nación-INFD. Documento para el Programa Nacional de Formación Permanente NUESTRA ESCUELA, 2013.

Las cifras de la Educación Inicial y sus modelos de organización (2010)Año 5/N 8/ Noviembre-Diciembre 2010.Boletín / DINIECE. Disponible en: http://repositorio.educacion.gov.ar:8080/dspace/bitstream/handle/123456789/109904/b olet\%C3\%ADn\%208.pdf

LEY N 27 045/14. Educación Inicial.

Currículum para la Educación Inicial de la Provincia del Chaco (2013) Ministerio de Educación, Cultura, Ciencia y Tecnología de la Provincia del Chaco.

Connell, Robert William (1997) Escuelas y Justicia Social. Madrid: Morata.

Cullen, Carlos (2009) Entrañas éticas de la identidad docente. Bs. As. La Crujía. (1997) Crítica de las razones de educar. Bs. As.: Paidós.

Davini, María Cristina (2006) La formación docente en cuestión: política y pedagogía. Bs. As: Paidós.

Dussel, Inés (1997) "El currículum y la sociedad", en DUSSEL, I. Currículum, humanismo y democracia en la enseñanza media (1863-1920) Oficina de Publicaciones del CBC, UBA - FLACSO.

\section{Notas}

\footnotetext{
'Ver APPLE, M. W. "El neoliberalismo y la naturalización de las desigualdades sociales". En: APPLE, M. W., DA SILVA, T.T. y GENTILI, P. (1997) Cultura, política y currículo. Bs. As.: Losada. Los estudios de Kaplan (1997/2008), entre otros, acerca de las representaciones de los docentes sobre la inteligencia de los alumnos, dan cuenta de los efectos de la reproducción de la lógica selectiva discriminatoria, en Argentina.

ii El nombre proviene de la identificación del grupo fundador del movimiento, con los sectores más pobres de Brasil, que habitan las villas o favelas.

iii Estas políticas se plasmaron en nuevos acuerdos de cooperación económica como UNASUR (Unión de Naciones Sudamericanas), el Consejo Sudamericano de Defensa, el Banco del Sur, SUCRE (Sistema Unificado de Compensación de Reservas) y la reorganización del MERCOSUR. El ALBA (Alternativa Bolivariana para América) impulsado por Venezuela, reemplazó al ALCA (Acuerdo de Libre Comercio de las Américas), impulsado por EEUU. La conformación de un bloque de países latinoamericanos, posibilitó
} 
un reposicionamiento político de los países aliados, que permitió negociar con las potencias mundiales, en mejores condiciones.

iv Ministerio de Educación de la Nación. Fortalecimiento y ampliación del derecho a la educación. 2015.

"Ministerio de Educación de la Nación-INFD. Documento para el Programa Nacional de Formación Permanente NUESTRA ESCUELA, 2013, MIMEO.

vi Las escuelas de Gestión Social constituyen, en el marco de los movimientos sociales de origen, instituciones comunitarias fundamentales en la organización y concreción del derecho a la educación. Se ubican geográficamente en los lugares de origen de las organizaciones territoriales que se desarrollaron en el seno de los barrios pobres- periféricos del gran Resistencia como consecuencia de los efectos excluyentes de las políticas neoliberales en los '90, que implicaron la retirada del Estado como garante de los derechos sociales básicos, entre ellos el derecho a la educación. Son resultado de las políticas de inclusión socioeducativa desarrolladas por el gobierno provincial en la década pasada, para sectores que tradicionalmente no accedían a la El. Tienen una organización institucional, prácticas de enseñanza y dinámicas internas particulares, que componen una modalidad de gestión escolar específica, que marca hoy una impronta en el campo educativo de la provincia del Chaco, donde hoy existen 4 EGS, una de ellas de Gestión Social Indígena.

vii Programa de formación docente gratuita y en ejercicio, para todos los docentes del país, desarrollado entre 2014/2015, aprobado por unanimidad por el Consejo Federal de Educación, organismo que reúne a todos los ministros de educación del país (CFE-RES. 201-13) y contó con Acuerdo Paritario suscripto por todos los sindicatos docentes con representación nacional. 